\title{
Effects of Surfactant Subfractions on Preterm Rabbit Lung Function
}

\author{
TAKAKO YAMADA, MACHIKO IKEGAMI, AND ALAN H. JOBE
}

Harbor-UCLA Medical Center, Department of Pediatrics, Division of Neonatology, Torrance, California 90509

\begin{abstract}
Surfactant isolated from adult rabbits was separated into large aggregate forms (LA) and small aggregate forms $(\mathrm{SA})$ by centrifugation at $40000 \times \mathrm{g} . \mathrm{LA}$ contain SP-A and the surfactant lipophilic proteins SP-B and SP-C and are surface-active in vitro, whereas SA lack the surfactant proteins and have poor surface properties. Premature rabbits were treated with $\mathrm{LA}$ or $\mathrm{SA}$ and ventilated to evaluate the effects of LA and SA in vivo. There were dose-response effects of LA at doses between 10 and $50 \mathrm{mg}$ total lipid/kg: dynamic compliances increased from 0.4 to $0.8 \mathrm{~mL} / \mathrm{cm} \mathrm{H}_{2} \mathrm{O} / \mathrm{kg}$ and pressure-volume curves improved significantly, whereas SA did not improve any of the measurements at any dose. Organic solvent extracts of SA made up into $\mathrm{LA}$ also did not improve in vivo function. When 1.5\% SP-B and SP-C isolated from calf surfactant was added to organic solvent extracts of SA, the surfactant had good in vitro surface properties and increased maximum lung volumes. However, this surfactant did not improve dynamic compliances or lung stability on pressurevolume curves. Because the lipids from SA seemed to limit the compliance response, we tried to identify differences in lipids from LA and SA. Phospholipids from SA reconstituted with SP-BC did not function well in vivo, whereas phospholipids from LA with SP-BC were similar to LA surfactant. The neutral lipid fractions from LA or SA did not contribute very much to or inhibit function. Fatty acid composition of the phospholipids and phosphatidylcholine from LA and SA were not remarkably different. We conclude that subtle compositional differences in the phospholipids or difficulties with reconstriction of the lipids with SP-BC prevents in vivo function of SA surfactant. (Pediatr Res 27: 592-598, 1990)
\end{abstract}

\section{Abbreviations}

LA, large aggregate surfactant

SA, small aggregate surfactant

SP-A, surfactant protein-A

SP-B, sufactant protein-B

SP-C, surfactant protein-C

SP-BC, mixture of SP-B and SP-C

LE-LA, lipid extract of large aggregate surfactant

LE-SA, lipid extract of small aggregate surfactant

DPPC, dipalmitoylphosphatidylcholine

PG, phosphatidylglycerol

PA, palmitic acid

Received October 16, 1989; accepted February 15, 1990.

Correspondence: Alan H. Jobe, M.D., Ph.D., Harbor-UCLA Medical Center, Department of Pediatrics, Division of Neonatology A-17 Annex, 1000 W. Carson St., Torrance, CA 90509.

Supported by grants HD-11932 and HD-12714 from the Departments of Health and Human Services.
Surfactant as recovered by alveolar wash from healthy adult animals is a mixture of surfactant phospholipids and proteins in multiple aggregate sizes (1). Several investigators have shown that LA and SA of surfactant separated by centrifugation have different biochemical and morphologic characteristics and different surface properties in vitro (1-4). LA of surfactant composed of mainly tubular myelin and large multilamellar vesicles are surface active, whereas the SA are much less surface active. There are no differences in phospholipid composition of the different aggregate forms; however, the surfactant-specific protein content (SP-A, -B, and -C) differs between the aggregate forms of surfactant. LA contain most of the surfactant proteins recovered by alveolar wash, whereas SA contain very little surfactant protein (2). Recently, several groups demonstrated that surfactant lipophilic proteins SP-B and SP-C are essential components of surfactant extracts or phospholipid mixtures for the achievement of low surface tensions and rapid adsorption (510). However, in vitro properties do not necessarily correlate well with in vivo responses (11). Therefore, we asked what the effects of LA and SA surfactant were when tested in vivo in preterm ventilated rabbits. We also wanted to know if any differences might depend on the aggregate forms, the presence of SP-B and SP-C, or other factors.

\section{MATERIALS AND METHODS}

Recovery of LA or SA surfactant. New Zealand White rabbits $(1.5-2.0 \mathrm{~kg})$ were killed with pentobarbital. The aorta of each rabbit was cut, the chest was opened, and a tube was tied in the trachea. The lungs were filled with room temperature $0.15 \mathrm{M}$ $\mathrm{NaCl}$, which was then withdrawn with a syringe. This procedure was repeated three times and the three alveolar washes were pooled. Alveolar washes were centrifuged at $140 \times g$ for $10 \mathrm{~min}$ in a Sorvall SS-34 rotor to remove cellular debris. The supernatant was centrifuged at $40000 \times g$ for $15 \mathrm{~min}(12)$. The supernatant from the $40000 \times g$ centrifugation was concentrated approximately 150 - to 200 -fold by ultrafiltration (Diaflo, XM300, Amicon Corp., Danvers, MA) and used as SA surfactant. The pellet was resuspended with $0.15 \mathrm{M} \mathrm{NaCl}$ and again centrifuged at $40000 \times g$ for $15 \mathrm{~min}$ in a Sorvall SS-34 rotor (Dupont Instruments, Wilmington, DE) over $1 \mathrm{M}$ sucrose in $0.15 \mathrm{M} \mathrm{NaCl}$. The LA then was collected from the interface of $0.15 \mathrm{M} \mathrm{NaCl}$ and sucrose, diluted with $0.075 \mathrm{M} \mathrm{NaCl}$ and centrifuged at $40000 \times g$ for $20 \mathrm{~min}$ in a SS-34 rotor. The pellet, resuspended in $0.075 \mathrm{M} \mathrm{NaCl}$, was then used for animal testing because suspending fluid of lower ionic strength promoted fluid adsorption in adult rabbit lung (13). The concentrations of LA and SA were adjusted to $7.7 \mathrm{mg}$ total lipid/mL before use.

Change of aggregate size of organic solvent extracts of $L A$ and $S A$. The lipids of LA and SA were extracted with chloroform:methanol $(2: 1, \mathrm{vol} / \mathrm{vol})$ and dried with a rotary evaporator, and $0.075 \mathrm{M} \mathrm{NaCl}$ was added to the lipid extracts. A suspension was prepared by adding glass beads to the flask and shaking the flask by hand at room temperature to make large multilamellar surfactant aggregates. After suspension, the surfactants were cen- 
trifuged at $40000 \times g$ for $15 \mathrm{~min}$, and the material that sedimented was resuspended in $0.075 \mathrm{M} \mathrm{NaCl}$ to a concentration of $7.7 \mathrm{mg}$ lipid $/ \mathrm{mL}$. The final suspensions of both fractions then only contained sedimentable aggregates that contained $91 \%$ of the original LE-LA and $86 \%$ of the LE-SA.

Isolation of $S P-B C$. Surfactant isolated from alveolar washes of newborn calves as previously described (14) was extracted two times with chloroform:methanol $(2: 1, \mathrm{vol} / \mathrm{vol})$. The chloroform phase was dried and resuspended with a small volume of chloroform:methanol $(2: 1, \mathrm{vol} / \mathrm{vol})$ from which SP-B and SP-C were then isolated together according to Takahashi and Fujiwara (15). Solutions containing approximately $400 \mathrm{mg}$ total lipid were applied to a $2.5 \times 100 \mathrm{~cm}$ column of Sephadex LH-20 (Pharmacia Fine Chemicals Ltd., Uppsala, Sweden) that had been equilibrated with chloroform:methanol $(2: 1, \mathrm{vol} / \mathrm{vol})$. The proteins were then eluted with the same solvent at a flow rate of $0.34 \mathrm{~mL} / \mathrm{min}$ at room temperature. The effluent was monitored at $280 \mathrm{~nm}$, and fractions from the first $2 / 3$ of the first peak that separated protein from phospholipids were combined and analyzed for protein in $1 \%$ SDS by the technique of Lowry et al. (16) using BSA in $1 \%$ SDS as the standard. SDS polyacrylamide gel electrophoresis was carried out according to the method of Laemmli (17) on $1.5-\mathrm{mm}$ thick slab gels containing $15 \%$ polyacrylamide. The sample buffer contained $10 \%$ 2-mercaptoethanol, and a silver stain (Bio-Rad Laboratories, Richmond, CA) was used to visualize the proteins.

Preparation of surfactant with $S P-B C$. SP-BC in chloroform:methanol $(2: 1, \mathrm{vol} / \mathrm{vol})$ was mixed with LE-SA or DPPC:PG:PA (68:22:10 by wt; Sigma Chemical Co., St. Louis, $\mathrm{MO})$ in chloroform:methanol $(2: 1, \mathrm{vol} / \mathrm{vol})$ to achieve $1.5 \%$ by wt SP-BC in the lipid mixture. The mixtures were dried and dispersed in $0.075 \mathrm{M} \mathrm{NaCl}$ at a concentration of $7.7 \mathrm{mg}$ total lipid/mL with glass beads to make multilamellar lipid-protein aggregates.

Separation of phospholipids and neutral lipids. Phospholipids and neutral lipids from LA or SA were separated by thin-layer chromatography using hexane:diethyl ether:formic acid (40:10:1, $\mathrm{vol} / \mathrm{vol}$ ) as solvent. After visualization of spots with iodine vapor, spots of phospholipids and neutral lipids were scraped from plates separately. Lipids were recovered from the silica with chloroform:methanol $(2: 1, \mathrm{vol} / \mathrm{vol})$ by filtration. Phospholipids (PL) or neutral lipids (NL) were used to make surfactant suspensions as follows: phospholipids alone from LA or SA, reconstitution of phospholipids from SA plus $7.5 \%$ by wt neutral lipids from LA (SA-PL + LA-NL), or phospholipids from LA plus $7.5 \%$ by wt neutral lipids from SA (LA-PL + SA-NL). SP-BC (1.5\% by wt) was added to all suspensions.

Fatty acid composition. The fatty acid compositions were determined after methylation with boron trifluoride in methanol for total phospholipids and phosphatidylcholine isolated by thinlayer chromatography from SA and LA. The fatty acid methyl esters were separated by gas-liquid chromatography at $180^{\circ} \mathrm{C}$ using a glass column packed with $10 \%$ GP on chromosorb WAW (Supelco, Inc., Bellefonte, PA).

Surface activities. Minimum and maximum surface tensions of each surfactant were measured with Wilhelmy balance. The trough was filled with $0.15 \mathrm{M} \mathrm{NaCl}$, and $60 \mathrm{nmol}$ of phospholipid from each surfactant was applied to the surface. The balance was cycled from a maximum surface area of $64 \mathrm{~cm}^{2}$ to a minimum surface area of $12.8 \mathrm{~cm}^{2}$ in $3 \mathrm{~min}$ at $37^{\circ} \mathrm{C}$.

Preterm ventilated rabbit model. Pregnant New Zealand White rabbits at $27 \mathrm{~d}$ gestational age were preanesthetized with $4 \mathrm{mg}$ diazepam given by i.v. injection and then given spinal anesthesia with a mixture of $1 \mathrm{~mL} 2 \%$ lidocaine and $1 \mathrm{~mL} 0.5 \%$ bupivacaine. Fetuses were delivered by cesarean section, weighed, and anesthetized with an intraperitoneal injection of a mixture of 10 $\mathrm{mg} / \mathrm{kg}$ ketamine and $0.1 \mathrm{mg} / \mathrm{kg}$ acepromazine. A tube made from an 18-gauge needle then was tied in the trachea of each animal. The rabbits were treated with $6.5 \mathrm{~mL} / \mathrm{kg}$ suspensions of the different surfactants or Survanta (Abbott Laboratories, N.
Chicago, IL), a surfactant prepared from calf lung and used clinically for the treatment of respiratory distress syndrome (18). At least one fetus from each litter was used as an untreated control. Ventilation was started with an anesthesia bag delivering three to four breaths. The rabbits then were placed in a series of plastic temperature-controlled ventilator plethysmographs (19). Rabbits were ventilated for 15 min with $100 \%$ oxygen at rate of 30 breaths/min with an inspiratory time of $1 \mathrm{~s}$ and an endexpiratory pressure of $0 \mathrm{~cm} \mathrm{H}_{2} \mathrm{O}$. The initial peak inspiratory pressure was $35 \mathrm{~cm} \mathrm{H}_{2} \mathrm{O}$, and peak pressure was then individually regulated to adjust the tidal volume to $10-12 \mathrm{~mL} / \mathrm{kg}$ as measured with a pneumotachometer. Dynamic compliance was calculated by dividing tidal volume per $\mathrm{kg}$ body wt by peak inspiratory pressure. After $15 \mathrm{~min}$ of ventilation, the endotracheal tube was plugged for 5 min to allow absorption atelectasis to occur, then the rabbits were killed with intrathecal lidocaine.

Pressure-volume curves. The rabbits were temperature-controlled at $37^{\circ} \mathrm{C}$, and pressure was increased from 0 to $35 \mathrm{~cm} \mathrm{H}_{2} \mathrm{O}$ by $5-\mathrm{cm} \mathrm{H}_{2} \mathrm{O}$ increments with maintenance of the pressure for $30 \mathrm{~s}$ at each level. Pressure then was lowered at the same rate, and volumes at all pressures were recorded. The measured volumes were corrected for air compression of the system. After one pressure-volume cycle, the chests were opened and alveolar washes were carried out with $0.15 \mathrm{M} \mathrm{NaCl}$ (19). The alveolar wash procedure was repeated five times, the washes were pooled and the total volume was measured. These alveolar washes were used for the measurements of total phospholipid and total protein.

Analytic procedures. Aliquots of the different surfactants were extracted with chloroform:methanol $(2: 1, \mathrm{vol} / \mathrm{vol})$ and the lipid extracts were assayed for phosphorus according to Bartlett (20). Total protein in the alveolar washes was measured according to Lowry et al. (16). The phospholipid composition of the LE-LA and LE-SA was measured after two-dimensional thin-layer chromatography of the lipid extracts (21). The phospholipids were identified in iodine vapor, and phosphorus content of the phospholipids was measured.

Data analysis. All values are expressed as means \pm SEM. Between-group comparisons were by one-way analysis of variance followed by the Student-Newman-Keuls multiple comparison procedure. The $t$ test was used for comparisons versus control values.

\section{RESULTS}

Characteristics of surfactants. After centrifugation of alveolar washes of adult rabbits, $43 \%$ of the phospholipid was recovered as LA and $57 \%$ as SA. Total protein in alveolar washes measured according to Lowry et al. (16) was $0.6-0.8 \mathrm{mg} / \mathrm{kg}$ for LA and $6.9-9.2 \mathrm{mg} / \mathrm{kg}$ for SA. The protein to phospholipid ratio for the LA was $0.24 \mathrm{mg}$ protein $/ \mathrm{mg}$ phospholipid, whereas there was a higher ratio of $2.02 \mathrm{mg}$ protein $/ \mathrm{mg}$ phospholipid for SA. The phospholipid compositions of LA and SA fractions were similar, although there was an increase in lysophosphatidylcholine from $1 \%$ in LA to $4 \%$ in small SA (Table 1). The SP-BC isolated for the reconstituted surfactant gave one wide band at about $6 \mathrm{kD}$ by SDS-polyacrylamide gel electrophoresis and other protein bands were not seen.

Fatty acid composition. The fatty acid composition of total phospholipids were measured for pooled samples of SA and LA and for phosphatidylcholine isolated from these fractions (Table 2 ). There were no striking differences in fatty acid compositions for either the total phospholipids or phosphatidylcholines from the LA and SA surfactants. The resulting total percent saturated fatty acids was $66 \%$ for SA and $71 \%$ for LA phospholipids and $77 \%$ for SA and $74 \%$ for LA phosphatidylcholine.

Surface tensions. Minimum surface tensions for LA, LE-SA with SP-BC, and Survanta were lower than for the other surfactants $(p<0.01$, Table 3$)$. Although the lipid extraction procedure removed SP-A from the surfactant, LE-LA still lowered the 
Table 1. Percent composition of phospholipids (mean \pm SEM)*

\begin{tabular}{ccccccccc}
\hline & $n$ & PC & PG & PI & PE & Lyso PC & SM & Others \\
\hline LA & 5 & $82.0 \pm 0.6$ & $5.5 \pm 0.2$ & $4.0 \pm 0.4$ & $3.9 \pm 0.1$ & $1.1 \pm 0.1$ & $0.9 \pm 0.1$ & $1.7 \pm 0.1$ \\
SA & 3 & $84.4 \pm 0.5$ & $4.3 \pm 0.1$ & $3.5 \pm 0.6$ & $2.7 \pm 0.1$ & $4.0 \pm 0.1$ & $1.0 \pm 0.1$ & $1.4 \pm 0.1$ \\
\hline
\end{tabular}

* PC, phosphatidylcholine; PI, phosphatidylinositol; PE, phosphatidylethanolamine; SM, sphingomyelin.

Table 2. Percent composition of fatty acids (mean \pm SEM)

\begin{tabular}{|c|c|c|c|c|c|c|c|c|c|}
\hline & $\mathrm{C} 14: 0$ & $\mathrm{C} 16: 0$ & $\mathrm{C} 16: 1$ & $\mathrm{C} 18: 0$ & C18:1 & $\mathrm{C} 18: 2$ & $\mathrm{C} 18: 3$ & Others & Saturation (\%) \\
\hline \multicolumn{10}{|l|}{ Phospholipids } \\
\hline $\mathrm{LA}(n=3)$ & $1.4 \pm 0.4$ & $67.2 \pm 2.7$ & $5.8 \pm 0.8$ & $2.4 \pm 1.1$ & $16.7 \pm 0.3$ & $6.0 \pm 1.6$ & & $0.4 \pm 0.3$ & $71.0 \pm 1.6$ \\
\hline $\mathrm{SA}(n=3)$ & $0.9 \pm 0.6$ & $61.6 \pm 2.0$ & $5.5 \pm 1.4$ & $3.3 \pm 1.4$ & $19.9 \pm 0.3$ & $8.5 \pm 2.0$ & & $0.3 \pm 0.3$ & $65.8 \pm 0.6$ \\
\hline \multicolumn{10}{|c|}{ Phosphatidylcholine } \\
\hline $\operatorname{LA}(n=3)$ & $2.6 \pm 0.2$ & $69.7 \pm 0.7$ & $5.4 \pm 0.5$ & $1.6 \pm 0.4$ & $15.3 \pm 1.4$ & $5.0 \pm 0.9$ & & $0.6 \pm 0.2$ & $73.8 \pm 1.1$ \\
\hline $\mathrm{SA}(n=3)$ & $2.2 \pm 0.7$ & $73.1 \pm 1.2$ & $4.6 \pm 1.4$ & $2.2 \pm 1.0$ & $13.1 \pm 1.2$ & $3.4 \pm 0.5$ & $1.1 \pm 1.1$ & $0.5 \pm 0.2$ & $77.4 \pm 1.4$ \\
\hline
\end{tabular}

Table 3. Maximum and minimum surface tensions (dynes $/ \mathrm{cm}$ ) of surfactants (mean $\pm S E M)$

\begin{tabular}{llcr}
\hline & $n$ & $\begin{array}{c}\text { Maximum surface tension } \\
\text { (dynes/cm) }\end{array}$ & $\begin{array}{c}\text { Minimum surface tension } \\
\text { (dynes/cm) }\end{array}$ \\
\hline LA & 4 & $38.4 \pm 2.8$ & $4.5 \pm 0.6$ \\
LE-LA & 3 & $31.3 \pm 3.1$ & $9.0 \pm 0.8$ \\
SA & 3 & $54.0 \pm 1.9$ & $17.8 \pm 0.4$ \\
LE-SA & 3 & $53.0 \pm 1.1$ & $20.1 \pm 0.6$ \\
LE-SA + SP-BC & 4 & $32.1 \pm 2.6$ & $4.2 \pm 0.2$ \\
DPPC:PG:PA (68:22:10) + SP-BC & 4 & $56.9 \pm 2.8$ & $11.9 \pm 0.5$ \\
Survanta & 3 & $48.1 \pm 3.4$ & $6.6 \pm 0.6$ \\
\hline
\end{tabular}

minimum surface tension to less than 10 dynes $/ \mathrm{cm}$. Organic solvent extraction of SA and resuspension into large multilamellar forms did not alter surface properties, and SA and LE-SA gave higher minimum surface tensions than all of the other surfactants $(p<0.01)$. The addition of SP-BC to LE-SA significantly lowered the minimum and maximum surface tensions to values comparable to that of the LA, demonstrating the anticipated effect of the proteins on the in vitro properties of the lipids.

In vivo effects of $L A$ and $S A$ surfactant. The surfactant dosedynamic compliance responses of LA and SA were tested in groups of seven to eight ventilated preterm rabbits at 10,20 , or $50 \mathrm{mg}$ total lipid/kg for each surfactant. The surfactants were diluted to administer the same saline volume to all animals. Compliance improved with increasing dose of LA, whereas there was no improvement in the animals given SA at any dose (Fig. $1 A$ ). The dose-response relationships for lung volume at $35 \mathrm{~cm}$ $\mathrm{H}_{2} \mathrm{O}$ pressure measured from pressure-volume curves were similar to the changes seen in dynamic compliance (Fig. $1 B$ ). Twenty and $50 \mathrm{mg}$ LA significantly increased volume relative to control rabbits $(p<0.01)$. There was no change from control in SAtreated animals.

Organic solvent-extracted $L A$ and $S A$ surfactant. The LA and SA were extracted and resuspended to form large multilamellar aggregates, defined by sedimentation at $40000 \times g$. The surfactant suspensions were tested at doses of $50 \mathrm{mg}$ total lipid/ $\mathrm{kg}$ in ventilated preterm rabbits. Dynamic compliance values at 15 min were the same for rabbits treated with SA or LE-SA as for the control animals (Fig. 2A). The effect on compliance of the LE-LA was intermediate between that of the LA and the controls, indicating an adverse effect of the extraction and resuspension procedure. SA and LE-SA did not improve the pressure-volume curves (Fig. $2 B$ ). The volume at $35 \mathrm{~cm} \mathrm{H} \mathrm{H}_{2} \mathrm{O}$ was significantly decreased for LE-SA relative to SA $(p<0.01)$. The effect of organic solvent extraction of LA on the volume at $35 \mathrm{~cm} \mathrm{H} \mathrm{H}_{2} \mathrm{O}$ was to modestly but significantly reduce the volume relative to LA; however, the pressure-volume curves for both LA and LELA demonstrated much more volume at 5 or $10 \mathrm{~cm} \mathrm{H}_{2} \mathrm{O}$ than did the other surfactants $(p<0.01)$.

Effects of addition of SP-BC. LE-SA with SP-BC and DPPC + $\mathrm{PG}+\mathrm{PA}$ with SP-BC did not improve dynamic compliance after
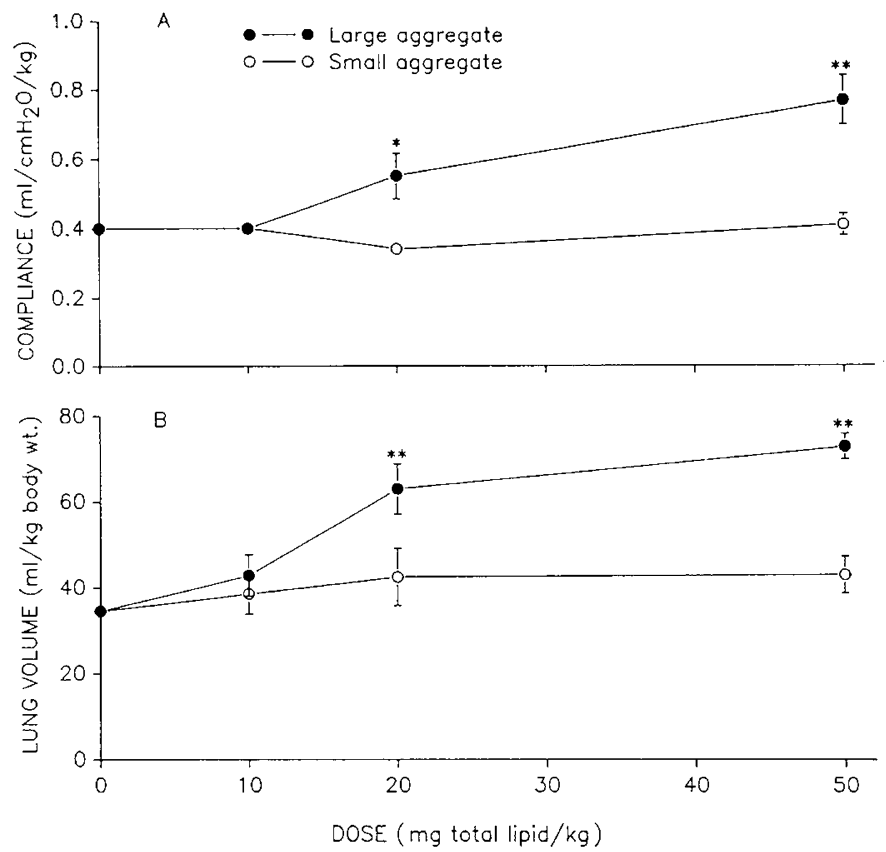

Fig. 1. Dose-response of dynamic compliance $(A)$ and maximal lung volumes at $35 \mathrm{~cm} \mathrm{H}_{2} \mathrm{O}$ pressure $(B)$ from the pressure-volume curves. Groups of seven to eight rabbits were studied for each dose of the large or small aggregate surfactant. LA surfactant significantly increased compliances and lung volumes at 20 and $50 \mathrm{mg}$ total lipid/ $\mathrm{kg}$ relative to both the control and SA $\left(* p<0.05,{ }^{* *} p<0.01\right)$.

15 min of ventilation, whereas Survanta improved compliance relative to these two surfactants or to the control $(p<0.01$, Fig. $3 A$ ). However, DPPC + PG + PA with SP-BC improved compliance at $5 \mathrm{~min}$ of ventilation to values similar to those of Survanta. This initial effect was similar to that found with LA. Lung volumes at $35 \mathrm{~cm} \mathrm{H}_{2} \mathrm{O}$ measured with the pressure-volume curves were the same for the two mixtures with SP-BC and Survanta and were larger than controls $(p<0.01$, Fig. $3 B)$. 

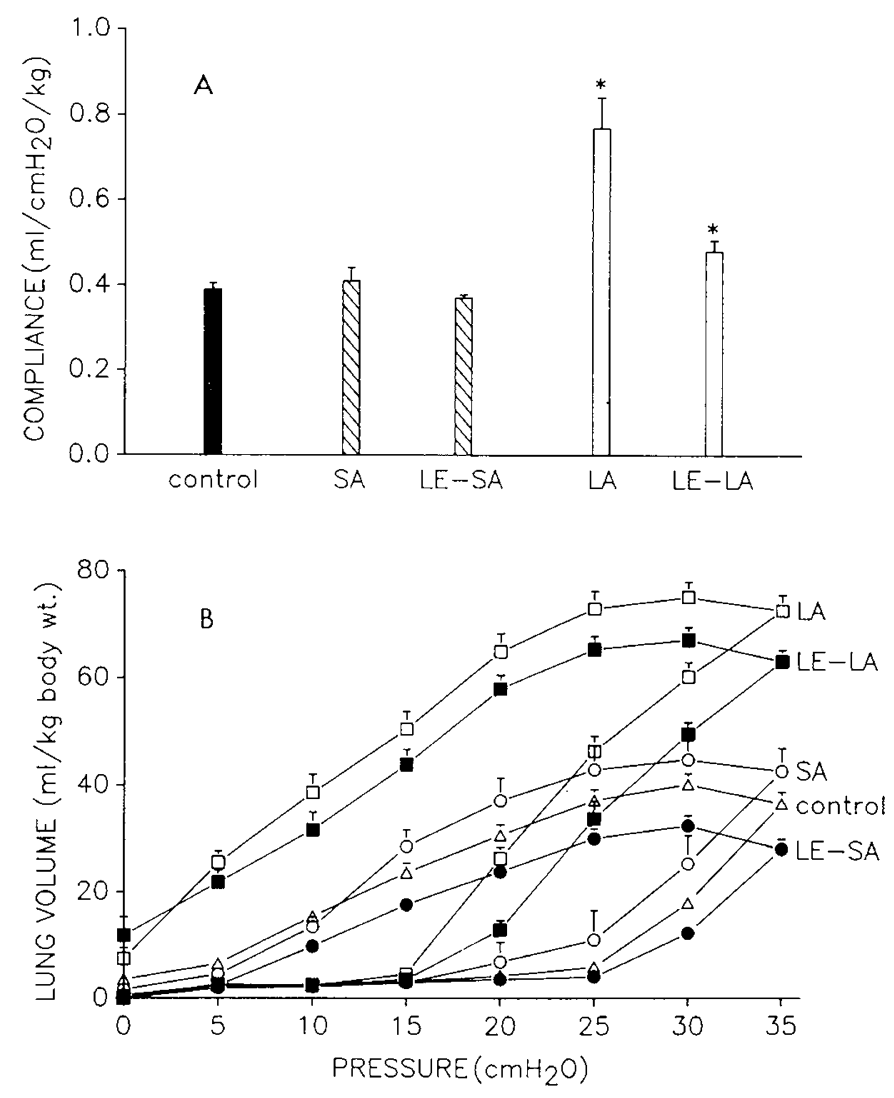

Fig. 2. Dynamic compliances $(A)$ and pressure-volume curves $(B)$ of organic solvent-extracted surfactants tested at $50 \mathrm{mg}$ total lipid/ $\mathrm{kg}$ in groups of seven to nine rabbits. SA did not improve compliance values $v s$ controls. LA and LE-LA improved compliance $v s$ control values $\left({ }^{*} p\right.$ $<0.01)$, and the value for LA was higher than for LE-LA $(p<0.01)$. Significant differences in volumes at $35 \mathrm{~cm} \mathrm{H}_{2} \mathrm{O}$ were found in the following order: LA $>$ LE-LA $>$ SA, control, and LE-SA $(p<0.01)$; and SA $>$ LE-SA $(p<0.01)$. Significant differences for volumes at $10 \mathrm{~cm}$ $\mathrm{H}_{2} \mathrm{O}$ were LA and LE-LA $>$ control, SA, and LE-SA $(p<0.01)$.

However, the lung volumes at 5 or $10 \mathrm{~cm} \mathrm{H}_{2} \mathrm{O}$ on the deflation limbs of the pressure-volume curves differentiated the three surfactants. Survanta treatments resulted in a more stable lung, whereas the lipid mixture or LE-SA with SP-BC did not stabilize the lungs at low pressures.

Effects of neutral lipids. Organic solvent extracts of LA and SA contained 5-10\% by wt neutral lipids. Removal of the neutral lipids from the LE-LA did not significantly alter compliance or volume at $35 \mathrm{~cm} \mathrm{H}_{2} \mathrm{O}$ but did decrease volume at $10 \mathrm{~cm} \mathrm{H}_{2} \mathrm{O}$ $(p<0.01)$ (Fig. 4). The neutral lipids from LE-SA, when added to the phospholipids from LE-LA, did not change the compliance values or the lung volumes at $35 \mathrm{~cm} \mathrm{H}_{2} \mathrm{O}$ but they did improve the lung volumes at $10 \mathrm{~cm} \mathrm{H}_{2} \mathrm{O}$. Removal of neutral lipids from LE-SA did not improve the responses to the phospholipids from LE-SA. Therefore, the neutral lipids from SA were not inhibitory to function. The neutral lipids from LE-LA did not improve the function of the phospholipids from LE-SA. Rather, the addition of the neutral lipids resulted in a decrease in volume at $35 \mathrm{~cm}$ $\mathrm{H}_{2} \mathrm{O}$.

Protein in alveolar washes. The amounts of protein in alveolar washes were different depending on the surfactants used to treat the animals (Fig. 5). Protein in the animals treated with LA, LELA, or Survanta was significantly lower than controls $(p<0.01)$. The animals given SA or LE-SA had about the same amount of protein as controls. The addition of SP-BC did not increase the protein recoveries very much relative to control values.

\section{DISCUSSION}

The surfactant secreted from lamellar bodies into the alveolar space exists in several different aggregate forms that have differ-
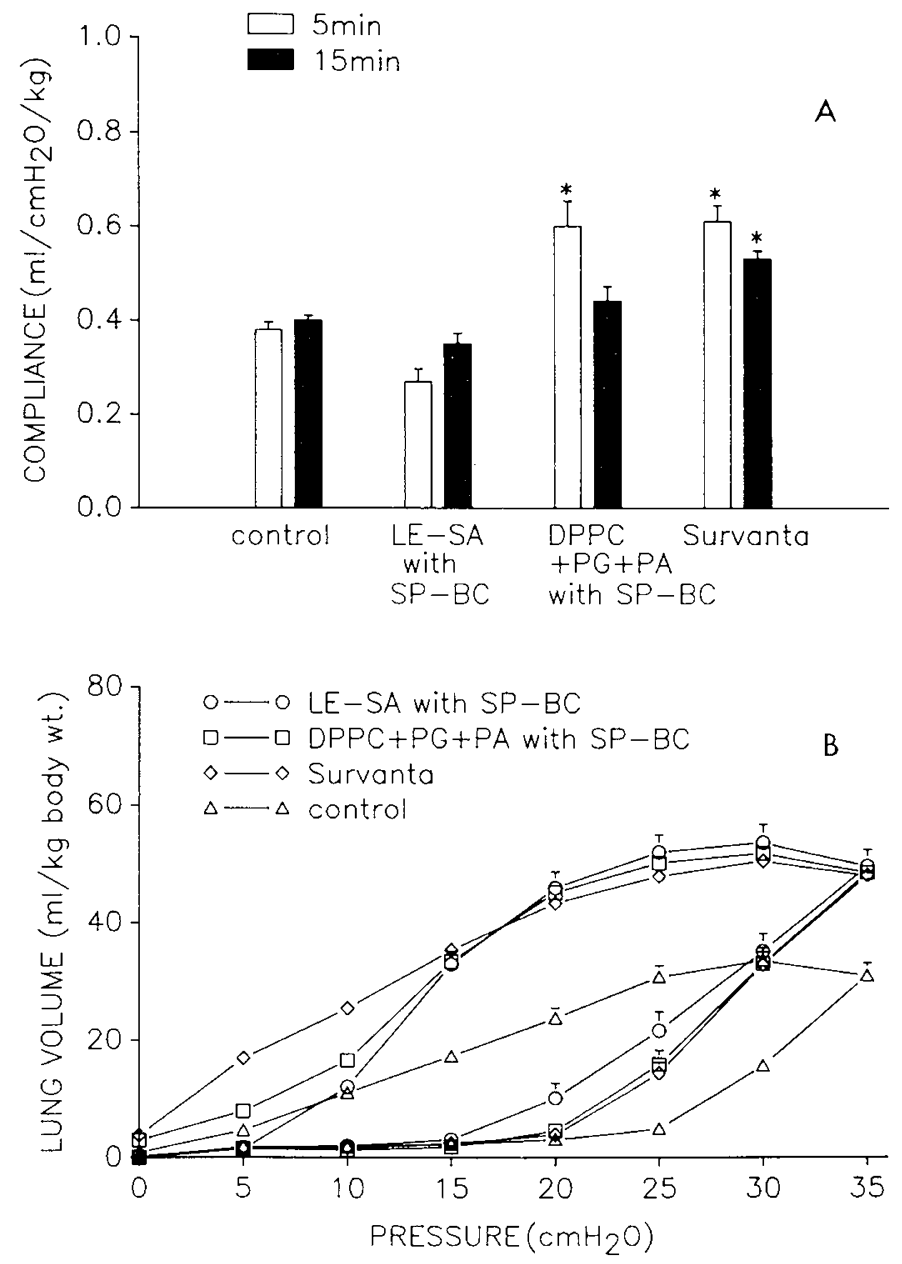

Fig. 3. Dynamic compliance at 5 and $15 \mathrm{~min}(A)$ and pressurevolume curves $(B)$ for organic solvent-extracted SA surfactant with SP$\mathrm{BC}$, the lipid mixture plus SP-BC and Survanta tested in groups of eight to 10 rabbits. The addition of $1.5 \%$ by wt SP-BC to an organic solvent extract of the small aggregate surfactant (LE-SA with SP-BC) improved lung volumes at $35 \mathrm{~cm} \mathrm{H}_{2} \mathrm{O}(p<0.01)$ but did not improve compliance and lung volumes at $10 \mathrm{~cm} \mathrm{H}_{2} \mathrm{O}$. The lipid mixture (DPPC + PG + PA) with SP-BC improved compliance at $5 \min \left({ }^{*} p<0.01\right)$ but not at 15 min relative to control. Lung volumes at $35 \mathrm{~cm} \mathrm{H}_{2} \mathrm{O}$ were improved with the lipid mixture with SP-BC $(p<0.01)$ and moderately improved at $10 \mathrm{~cm} \mathrm{H}_{2} \mathrm{O}$ relative to control $(p<0.05)$. Survanta improved compliance $\left({ }^{*} p<0.01\right)$, and lung volumes at 35 and $10 \mathrm{~cm} \mathrm{H}_{2} \mathrm{O}$ relative to control $(p<0.01)$.

ent biochemical and physiologic properties (1-4). Large aggregate surfactant containing tubular myelin and large vesicles has SPA, SP-B, and SP-C, adsorbs to an air-water interface rapidly, and lowers surface tensions to low values. In contrast, small aggregate surfactant composed of small vesicles contains very little of these proteins and adsorbs more slowly. In addition, there is a precursor-product relationship between LA and SA $(1,22)$. The morphologic changes from LA to SA accompanying the changes in surfactant protein content and surface properties imply a lifecycle of surfactant in the alveoli. Stevens et al. (23) and Bruni et al. (24) have demonstrated the time course for the appearance of SA in the airspaces of term rabbits after birth. Initially, almost all the alveolar phospholipids were in a large aggregate surfaceactive fraction. The smaller, less surface-active forms appeared over the first hours of life to achieve the ratio comparable to the adult rabbit by $24 \mathrm{~h}$. Similar but more rapid changes were noted for ventilated preterm lambs with and without surfactant treatment $(12,25)$. The function of these surfactant fractions is assumed to be abnormal in vivo because of the lack of surfactant 

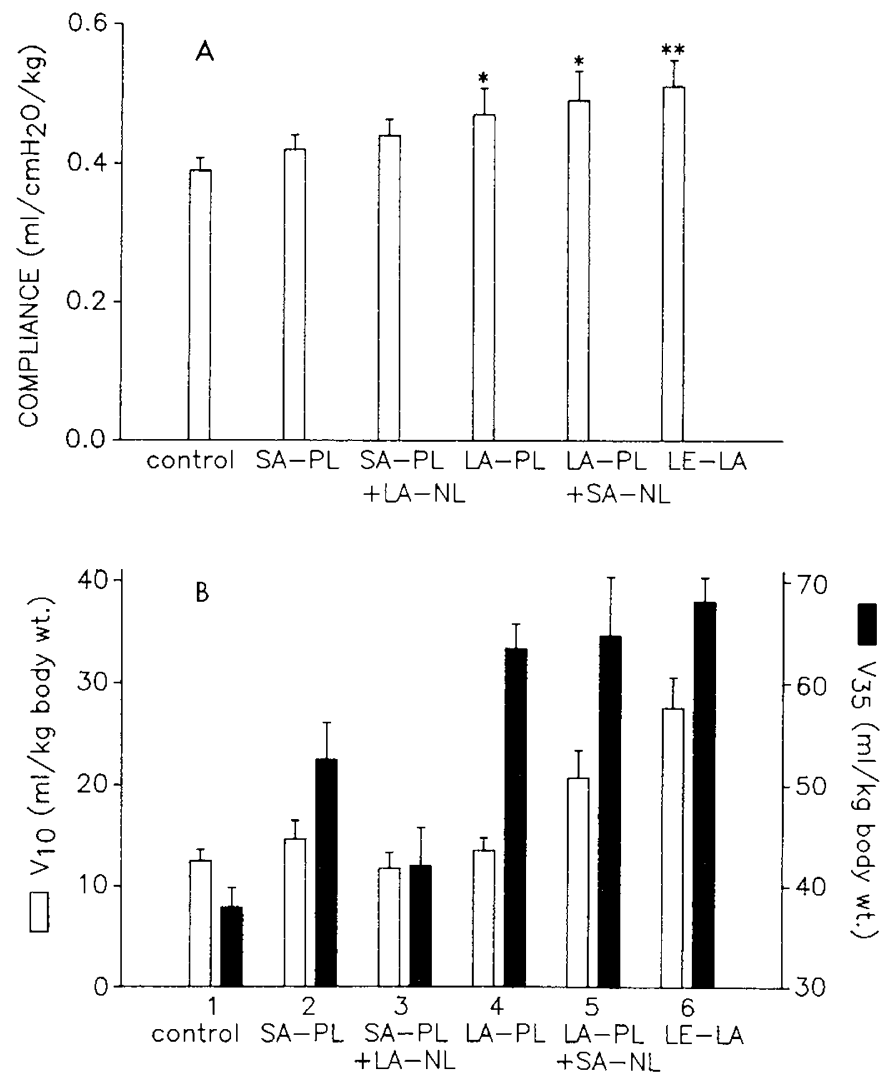

Fig. 4. Dynamic compliances $(A)$ and effects on volume at 10 and $35 \mathrm{~cm} \mathrm{H} \mathrm{H}_{2} \mathrm{O}(B)$ for mixtures of phospholipids (PL) and neutral lipids (NL) from LA or SA surfactants for groups of six to eight rabbits. SP-BC was added at $1.5 \%$ by wt to all mixtures except the organic solventextracted large aggregates (LE-LA). Large aggregate phospholipid (LA$\mathrm{PL}$ ) and LA-PL plus small aggregate neutral lipid (SA-NL) resulted in compliances that were equivalent to LE-LA and significantly better than control $\left({ }^{*} p<0.05,{ }^{* *} p<0.01\right)$. Significant differences for values for lung volumes at $35 \mathrm{~cm} \mathrm{H} \mathrm{H}_{2} \mathrm{O}$ were as follows: 6,5 , and $4>3$ and $l ; 6>2$; and $2>I(p<0.01)$. Significant differences for volumes at $10 \mathrm{~cm} \mathrm{H}_{2} \mathrm{O}$ were $6>1,2,3$, and 4 and $5>1(p<0.01)$.

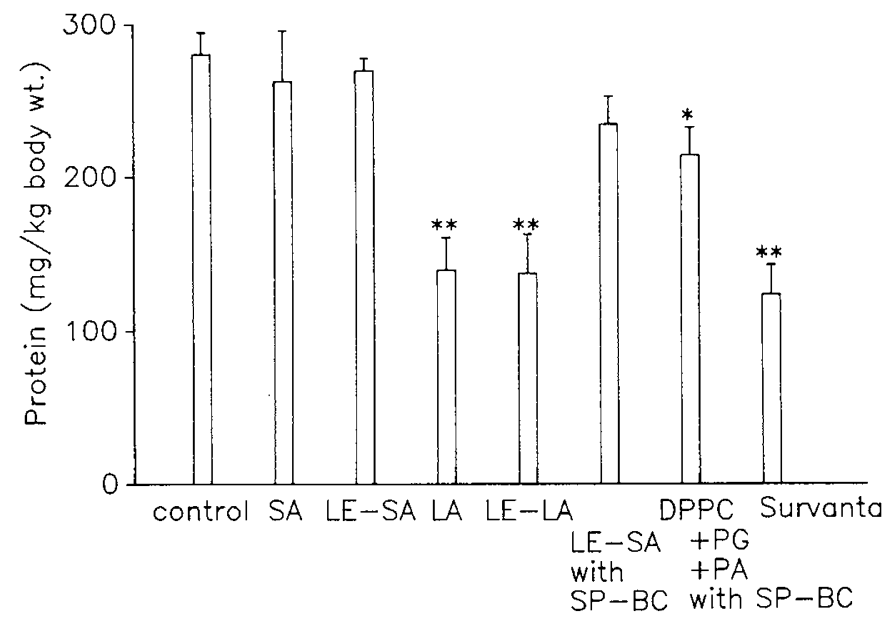

Fig. 5. Total protein content $(\mathrm{mg} / \mathrm{kg})$ in alveolar washes. LA, LE-LA, and Survanta decreased the amount of protein recovered $(* * p<0.01)$, whereas the effect was less but significant for the lipid mixtures plus SP$\mathrm{BC}\left({ }^{*} p<0.05\right)$. The different surfactants made from SA did not decrease protein recoveries. proteins (2), but this has not been evaluated. Therefore, the purpose for these experiments was to test the effect of large and small aggregate surfactant subfractions in a surfactant deficiency model, the preterm ventilated rabbit.

The large aggregate surfactant fraction isolated from rabbit alveolar washes was recovered in a manner similar to that used for the preparation of natural sufactant for experimental use (14). There was a dose-response effect for compliance in the animals treated with the LA fraction. The response at $50 \mathrm{mg}$ total lipid/ $\mathrm{kg}$ was higher than that at $20 \mathrm{mg}$ total lipid $/ \mathrm{kg}(p<0.01)$, whereas the dose-response effect for lung volume at $35 \mathrm{~cm} \mathrm{H} \mathrm{H}_{2} \mathrm{O}$ pressure was maximal at $20 \mathrm{mg}$ total lipid $/ \mathrm{kg}$, and there was no significant effect of increasing the dose to $50 \mathrm{mg}$ total lipid $/ \mathrm{kg}$. These observations indicate that static maximal distensibility of alveoli was accomplished at a dose of exogenous surfactant that was not optimal to achieve a good compliance in vivo. The surfactant dose-maximal lung volume relationship from pressure-volume curves was similar to those reported by Metcalfe et al. (26) for a lipid solvent-extracted surfactant from calf lung and by Seidner et al. (27) for rabbit surfactant. In contrast, the SA fraction did not improve dynamic compliance or pressure-volume curves at any dose up to $50 \mathrm{mg}$ total lipid $/ \mathrm{kg}$. This experiment demonstrated that small aggregate surfactant had no effect on preterm lungs. Because more protein remained in SA than LA after ultrafiltration, we could not rule out the possibility that the ineffectiveness of SA resulted from inhibition of surfactant function by these proteins (11).

Treatments with LA made from organic solvent-extracted SA did not improve in vitro function or in vivo function. This experiment made two points. The ineffectiveness of SA did not depend on the inhibition by nonspecific proteins and the aggregate size of the surfactant was not the critical variable. Such an effect could occur since small liposomes tend to adsorb to a surface very slowly (1). The organization of the lipids within the larger aggregates made from the organic solvent extracts of SA would not be the same as that found for the LA because of the lack of the surfactant proteins. For example, Suzuki et al. (28) recently demonstrated that synthetic lipid mixtures could be organized by surfactant proteins to form tubular myelin-like structures in vitro. The organic solvent extraction and resuspension did alter the effect of LA on dynamic compliance and maximum lung volumes at $35 \mathrm{~cm} \mathrm{H}_{2} \mathrm{O}$ to yield values similar to that of Survanta. The common variable for these two organic solvent-extracted surfactants was that SP-A was removed during the extraction procedure whereas SP-BC remained $(6,29)$. SP-A was shown to regulate surfactant phospholipid reuptake and secretion by type II cells $(30,31)$ and enhance adsorption of surfactants that contain SP-BC (32). Also, SP-A helped to form calcium-dependent lipid-protein aggregates thought to be critical to the formation of tubular myelin $(28,33)$. The absence of SPA may be the explanation for the altered function of LE-LA.

Several investigators demonstrated that synthetic lipid mixtures that contain SP-BC had excellent surface properties in vitro $(5-10)$, and such mixtures improved pressure-volume curves in preterm animals (34-36). These findings suggested that SP-BC was an essential component for the surface-active properties of surfactant. Although we found that LE-SA with SP-BC had low minimum surface tensions comparable to Survanta and increased lung volumes at $35 \mathrm{~cm} \mathrm{H}_{2} \mathrm{O}$ pressure, LE-SA with SP$\mathrm{BC}$ did not improve dynamic compliances in ventilated rabbits or lung volumes at low pressures on the deflation curves. Minimum surface tensions measured in vitro do not necessarily correlate with in vivo activities as pointed out previously (11). One explanation for this disparity could be that the physical properties of surfactant might change quickly in continuously ventilated lungs. This point was illustrated by the significant improvement in dynamic compliance at $5 \mathrm{~min}$ in the rabbits treated with the DPPC + PG + PA plus SP-BC mixture, a response that had disappeared by $15 \mathrm{~min}$. We have not seen such short-term responses with natural surfactants. 
The in vivo function of SA was not improved by organic solvent extraction that removed the nonspecific proteins or by reformation into LA with or without SP-BC, suggesting that the lipids were contributing to the lack of function. Natural surfactant contains both phospholipids and neutral lipids. Some investigators have demonstrated that reconstitution of phospholipids plus SP-BC improved surface properties without the need for neutral lipids $(34,35)$, whereas Tanaka et al. (36) reported that FFA and/or triglycerides improved the properties of synthetic surfactants. Saturated FFA such as PA or stearic acid improved surface properties more than did oleic acid. Neutral lipids were $5-10 \%$ by wt of both LA and SA fractions, with cholesterol being the principle lipid identified by thin-layer chromatography. However, removing the neutral lipids from LA did not alter compliances or maximum volumes at $35 \mathrm{~cm} \mathrm{H}_{2} \mathrm{O}$ on the pressurevolume curves. The only effect of neutral lipid removal was to decrease the volume at $10 \mathrm{~cm} \mathrm{H}_{2} \mathrm{O}$. Addition of neutral lipids from SA to large aggregate phospholipids tended to improve the volumes at low pressures without altering other measurements. There was very little impact of either the addition of SA-neutral lipids or the removal of LA-neutral lipids on in vivo function of the phospholipids from LA. The general conclusion was that the neutral lipids were not appreciably influencing the in vivo measurements made with these fractions derived from alveolar washes of adult animals.

Therefore, we are left with the primary difference between the function of the LA and SA possibly being the phospholipids. Phospholipid composition was similar in LA and SA (Table 1). The fatty acid composition of phosphatidylcholine from LA and SA also was quite similar and comparable to that previously reported for surfactant from dog lungs (37) or rabbit lungs (21). There was a modest increase in unsaturation in the total phospholipid fraction from SA. King (38) showed that lipid mixtures that contained both saturated phosphatidylcholine and dipalmitoylphosphatidylglycerol were bound to SP-A, and small decreases in the disaturated content resulted in decreased protein binding. It is possible that the change in the aggregate form of surfactant from large to small was accompanied by not only the loss of SP-A and SP-BC but also a small increase in unsaturated phospholipids that altered the interaction between SP-BC and the lipids. The increased lysophosphatidylcholine content of SA could also impact function as lysophosphatidylcholine is known to injure the lung and interfere with surface properties (39). An alternative possibility is that the SP-BC proteins were damaged during isolation and/or that the reformulation did not effectively reconstitute a surfactant from the SA lipids. The reconstitution of LE-SA with SP-BC did improve lung volumes, and the isolated proteins did enhance the in vivo function of the synthetic lipid mixture. Nevertheless, these mixing experiments could not definitively distinguish between subtle differences in the phospholipids of LA and SA, or complex lipid-protein interactions that altered function.

In summary, LA from the airspaces of healthy adult rabbits could be organic solvent-extracted and neutral lipid-depleted without much change in in vivo properties. SA did not improve lung function from that of control rabbits, and changes in aggregate size, addition of SP-BC, or removal of neutral lipids did not appreciably improve function, indicating that the phospholipids may have been limiting the reconstitution of the in vivo effects. Our studies demonstrate that there are complex interactions between lipids and proteins that are required for optimal function in the surfactant-deficient preterm lung.

\section{REFERENCES}

1. Magoon MW, Wright JR, Baritussio A, Williams MC, Goerke J, Benson GJ, Hamilton RL, Clements JA 1983 Subfractionation of lung surfactant: implications for metabolism and surface activity. Biochim Biophys Acta 750:18-31

2. Wright JR, Benson BJ, Williams MC, Goerke J, Clements JA 1984 Protein composition of rabbit alveolar surfactant subfractions. Biochim Biophys Acta 791:320-332

3. Baritussio A, Bellina L, Carraro R, Rossi A, Enzi G, Magoon M, Mussini I 1984 Heterogeneity of alveolar surfactant in the rabbit: composition, morphology, and labelling of subfractions isolated by centrifugation. Eur J Clin Invest 14:24-29

4. Gross NJ, Narine KR 1989 Surfactant subtypes in mice: characterization and quantitation. J Appl Physiol 66:342-349

5. Tanaka Y, Takei T, Kanazawa Y 1984 Lung surfactants II: effects of fatty acids, triacylglycerols and protein on the activity of lung surfactant. Chem Pharm Bull 31:4100-4109

6. Whitsett JA, Ohning BL, Ross G, Meuth J, Weaver T, Holm BA, Shapiro DL, Notter RH 1986 Hydrophobic surfactant-associated protein in whole lung surfactant and its importance for biophysical activity in lung surfactant extracts used for replacement therapy. Pediatr Res 20:460-467

7. Possmayer F, Yu S 1986 Reconstitution of surfactant activity by using the 6 $\mathrm{kDa}$ apoprotein associated with pulmonary surfactant. Biochem J 236:8589

8. Yu S, Chung W, Olafson RW, Harding PGR, Possmayer F 1987 Characterization of small hydrophobic proteins associated with pulmonary surfactant. Biochim Biophys Acta 921:437-448

9. Warr RG, Hawgood S, Buckley DI, Crisp TM, Schilling J, Benson BJ, Ballard PL, Clements JA, White RT 1987 Low molecular weight human pulmonary surfactant protein (SP5): isolation, characterization, and cDNA and amino sequences. Proc Natl Acad Sci 84:7915-7919

10. Notter RH, Shapiro DL, Ohning B, Whitsett JA 1987 Biophysical activity of synthetic phospholipids combined with purified lung surfactant 6000 dalton apoprotein. Chem Phys Lipids 44:1-17

11. Ikegami M, Agata Y, Elkady T, Hallman M, Berry D, Jobe A 1987 Comparison of four surfactants: in vitro surface properties and responses of preterm lambs to treatment at birth. Pediatrics 79:38-46

12. Jobe A, Ikegami M, Seidner S, Pettenazzo A, Ruffini L 1989 Surfactant phosphatidylcholine metabolism and surfactant function in preterm, ventilated lambs. Am Rev Respir Dis 139:352-359

13. Oyarzun MJ, Clements JA, Barutussio A 1980 Ventilation enhances pulmonary alveolar clearance of radioactive dipalmitoyl-phosphatidylcholine in liposomes. Am Rev Respir Dis 121:709-721

14. Jobe A, Ikegami M 1984 The prematurely delivered lamb as a model for studies of neonatal adaptation. In: Nathanielsz PW (ed) Animal Models in Fetal Medicine. Perinatology Press, Ithaca, NY, pp 1-30

15. Takahashi A, Fujiwara $T 1986$ Proteolipid in bovine lung surfactant: its role in surfactant function. Biochem Biophys Res Commun 135:527-532

16. Lowry OH, Rosebrough NJ, Farr AL, Randall RJ 1951 Protein measurement with the folin phenol reagent. J Biol Chem 193:265-275

17. Laemmli UK 1970 Cleavage of structural proteins during the assembly of the head of bacteriophage $T 4$. Nature 227:680-685

18. Horbar JD, Soll RF, Sutherland JM, Kotagal U, Alistair GS, Kessler DL, Little GA, Jobe AH, Ikegami M, Mullett MD, Myerberg DZ, McAuliffe TL, Lucey TF 1989 A multicenter randomized placebo-controlled trial of surfactant therapy for respiratory distress syndrome. N Engl J Med 320:959-965

19. Ikegami M, Berry D, Elkady T, Pettenazzo A, Seidner S, Jobe A 1987 Corticosteroids and surfactant change lung function and protein leaks in the lungs of ventilated premature rabbits. J Clin Invest 79:1371-1378

20. Bartlett GR 1959 Phosphorus assay in column chromatography. J Biol Chem $234: 466-468$

21. Jobe A, Kirkpatrick E, Gluck L 1978 Labeling of phospholipids in the surfactant and subcellular fractions of rabbit lung. J Biol Chem 253:3810-3816

22. Gross NJ, Narine KR 1989 Surfactant subtypes in mice: metabolic relationships and conversion in vitro. J Appl Physiol 67:414-421

23. Stevens PA, Wright JR, Clements JA 1987 Changes in quantity, composition, and surface activity of alveolar surfactant at birth. J Appl Physiol 63:10491057

24. Bruni R, Baritussio A, Quaglino D, Gabelli C, Benevento M, Ronchitti IP 1988 Postnatal transformations of alveolar surfactant in the rabbit: changes in pool size, pool morphology and isoforms of the $32-38 \mathrm{kDa}$ apolipoprotein. Biochim Biophys Acta 958:255-267

25. Ikegami M, Jobe A, Yamada T, Priestly A, Ruffini L, Rider E, Seidner S 1989 Surfactant metabolism in surfactant-treated preterm ventilated lambs. J Appl Physiol 67:429-437

26. Metcalfe IL, Burgoyne R, Enhorning G 1982 Surfactant supplementation in the preterm rabbit: effects of applied volume on compliance and survival. Pediatr Res 16:834-839

27. Seidner S, Pettenazzo A, Ikegami M, Jobe A 1988 Corticosteroid potentiation of surfactant dose response in preterm rabbits. J Appl Physiol 64:2366-2371

28. Suzuki Y, Fujita Y, Kogishi K 1989 Reconstitution of tubular myelin from surfactant lipids and protein associated with pig pulmonary surfactant. Am Rev Respir Dis 140:75-81

29. Taeusch HW, Keough KMW, Williams M, Slavin R, Steele E, Lee AS, Phelps D, Kariel N, Floros J, Avery ME 1986 Characterization of bovine surfactant for infants with respiratory distress syndrome. Pediatrics 77:572-581

30. Wright JR, Wager RE, Hawgood S, Dobbs L, Clements JA 1986 Surfactant apoprotein $\mathrm{M}_{\mathrm{r}}=26000-36000$ enhances uptake of liposomes by type II cells. J Biol Chem 262:2888-2894

31. Rice WR, Ross GF, Singleton FM, Dingle S, Whitsett JA 1987 Surfactant associated protein inhibits phospholipid secretion from type II cells. J Appl Physiol 63:692-698

32. Hawgood S, Benson BJ, Schilling J, Damm D, Clements JA 1987 Nucleotide 
and amino acid sequences of pulmonary surfactant protein SP 18 and evidence for cooperation between SP 18 and SP 28-36 in surfactant lipid adsorption. Proc Natl Acad Sci 84:66-70

33. Hawgood S, Benson BJ, Hamilton RL 1985 Effects of a surfactant-associated protein and calcium ions on the structure and surface activity of lung surfactant lipids. Biochemistry 24:184-190

34. Revak S, Merritt TA, Hallman M, Cochrane CG 1986 Reconstitution of surfactant activity using purified human apoprotein and phospholipids in vivo and in vitro. Am Rev Respir Dis 134:1258-1265

35. Yu S, Duncan W, Bhavnani B, Enhorning G, Possmayer F 1988 Effect of reconstituted pulmonary surfactant containing the 6000 -dalton hydrophobic protein on lung compliance of prematurely delivered rabbit fetuses. Pediatr Res 23:23-30

36. Tanaka Y Takei T, Aiba T, Masuda K, Kiuchi A, Fujiwara T 1986 Development of synthetic lung surfactants. J Lipid Res 27:475-485

37. King RJ, Clements JA 1972 Surface active materials from dog lung. II. Composition and physiological correlations. Am J Physiol 223:715-726

38. King RJ, Carmichael MC, Horowitz PM 1983 Reassembly of lipid-protein complexes of pulmonary surfactant. Proposed mechanism of interaction. Biol Chem 258:10672-10680

39. Niewoehner DE, Rice K, Sinha AA, Wangensteen D 1987 Injurious effects of lysophosphatidylcholine on barrier properties of alveolarepithelium. J Appl Physiol 63:1979-1986

\section{Announcements}

\section{Meeting Announcement}

The Society for Behavioral Pediatrics will conduct its 8th Annual Scientific Meeting on September 16-17, 1990 at the Westin Hotel in Denver, CO. The theme of this meeting will be "Behavioral Pediatrics and Education: A Vital Interface." The 1990 SBP Lectureship Address will be delivered by Bettye M. Caldwell, Ph.D. For further information and registration forms, please contact Ms. Noreen Spota at (215) 248-9168.

\section{Charles E. Culpeper Foundation Scholarships in Medical Science}

The Charles E. Culpeper Foundation is currently accepting applications for its 1991 Scholarships in Medical Science Program designed to support the career development of academic physicians.

Up to three awards of $\$ 100,000$ per year for 3 y will be made to United States medical schools on behalf of candidates who are U.S. citizens, who have received their M.D. degree from a U.S. medical school in 1982 or later, and who are judged worthy of support by virtue of the quality of their research proposals. All scientific research relevant to human health is eligible for consideration. No institution may nominate more than one candidate.

In selecting awardees, emphasis will be on identifying young physicians with clear potential for making substantial contributions to science as academic physicians. Since January 1988, nine physicians have been selected as Charles E. Culpeper Foundation Medical Scholars, three each in the years 1988, 1989, and 1990.

Deadline for applications is August 15, 1990. Awards will be announced by January 15, 1991 for activation on or about July 1, 1991. Application forms and instructions may be obtained by contacting the Charles E. Culpeper Foundation at 10 Stamford Forum, Stamford, CT 06901. 